\title{
Communication Skills for Children with Severe Learning Difficulties
}

\author{
Patricia Mutumburanzou \\ Jairos Jiri Centre for Special Needs Education \\ Robert Mugabe School of Education and Culture, Great Zimbabwe \\ University
}

Doi: 10.19044/ejes.v5no2a6

URL:http://dx.doi.org/10.19044/ejes.v5no2a6

\begin{abstract}
Individuals with severe learning disabilities have little or no speech and find it very difficult to communicate and learn new skills. Most of them were excluded from the education process due to the presumed inability to learn. However, it has been observed over time that individuals with severe learning disabilities (SLD) of all ages and types are able to learn to some degree. Because of the reduced ability to communicate they find it very difficult to interact with their environment and to cope independently hence they need constant support in daily living skills. Communication is critical even for individuals with SLD because it ensures the fulfillment of rights. This paper presents the communication skills that can be taught to children with severe learning disabilities to enable them to cope independently and to help improve the social interactions which are generally problematic or difficult.
\end{abstract}

Keywords: Communication, Severe Learning Disabilities, Rights, Skill, Assistive Technology, Assessment.

\section{Introduction}

One of the greatest achievements in human beings is the ability to communicate. Both speech and gestures can be part of a communication system. For all children communication begins before birth (Kirk, Gallagher and Anastasiow, 2006). Children with severe learning difficulties pose real challenges when it comes to communication. They usually experience profound delays and or failure to acquire speech and language. Children with severe learning difficulties may acquire speech or gestural systems and are very difficult to interact with. It is the task of this presentation to discuss the communication skills for children with severe learning difficulties. Some key terms are going to be defined. 
A severe learning disability- is a condition that causes significant and profound intellectual impairment and a very low Intelligent Quotient (I.Q.). It is generally accepted that an Intelligent Quotient of 50 constitutes a severe disability. Such Severe disabilities can be present from birth or acquired later in life through accidents or illness (Lowth, 2016).

Skill - is the ability to do something well arising from talent, training or practice. (www.definitions.net).

Assistive Technology (AT) refers to any tool or item that enhances the learning, mobility or communication skills of the individuals with disabilities (www .ehow.com)

Communication refers to how individuals share information including their thoughts and feelings. It is an act where one individual sends a message to another and that message is received and understood and acted upon (brookespublishing.com). It requires at least two individuals who understand each other to participate, the sender and the receiver. However, it should be noted that communication is not only about talking and listening. Individuals may convey messages through gestures, signing, body language, facial expression and even the tone of their voices (Parenting and Child Health 2018). Communication may be intentional or unintentional, may involve conventional or unconventional signals and may take linguistic or nonlinguistic forms. In other words communication may occur through spoken or other various modes.

\section{Children with Severe Learning Disabilities}

Most children with severe learning disabilities have significant multiple problems and may not be able to speak, hear, see, walk and so on. The inability to speak is one of the most formidable obstacles that children with severe learning difficulties face. It prevents them from interacting successfully with their environments and impedes the ability to learn from interactive experiences, things that the non- disabled do readily (Kirk, Gallagher and Anastasiow, 2006). The child with severe learning disabilities is usually less inquisitive, more withdrawn, less active and less fun than a child without disabilities. The child does not engage in play e.g. with objects or with peers.

However it is important to realize that being unable to speak does not mean that the individual is unable to communicate with others (Mirenda and Williams 1990). The child with severe learning disabilities has to rely on nonlinguistic forms of communication which may be very difficult to identify, interpret and understand. In most cases, the child is not able to express his or her own needs and feelings. He or she may communicate by adjusting the body, making gestures, facial expressions, eye blinks, eye gazes, making noise 
and so on. For example a child may stare at a colleague to indicate the need to 'play'(Mirenda and Willliams, 1990).

The critical factor is whether the colleague has the ability to identify and correctly interpret the child's efforts in communication. The child's communication skills may be difficult to recognize. It is crucial to try and pick the child's attempts at communication because, if they go unnoticed for too long, the child may give up trying. One can even observe the child on a video so as to understand his or her behavior for example, when he or she is hungry or upset (www./lcommunicatetherapy.com). Therefore when working with children with severe learning disabilities observe, focus on body movements, facial expression and record any findings. Go on to examine what triggered the movement or the vocalization. By keeping a running record, it may be possible to discern that certain things elicit certain responses (www./lcommunicatetherapy.com). Thus all individuals communicate in some way or another, however, the effectiveness and efficiency of this communication may vary with the number of individuals and environmental factors. Furthermore, some individuals with severe learning disabilities develop unconventional modes of communication. It is the responsibility of all individuals who interact with individuals with severe learning disabilities to recognize the communication efforts produced by the child and seek ways to promote the effectiveness of communication by and with those individuals (Mirenda and Williams,1990).

It becomes absolutely essential that parents, teachers, social workers and other professionals should be knowledgeable about SLD and should be prepared to help the pupils who are suffering from the disability and assist them in overcoming challenges and live happy full lives (Cowder, 2010).

\section{The Communication Bill of Rights}

This group of children is covered by the Communication Bill of Rights which states that all persons, regardless of the extent of severity of their disability, have a basic right to affect, through communication, the conditions of their own existence (www.asha.org/policy). Beyond this general right, a number of specific communication rights should be ensured in all daily interactions involving persons who have severe disabilities. 

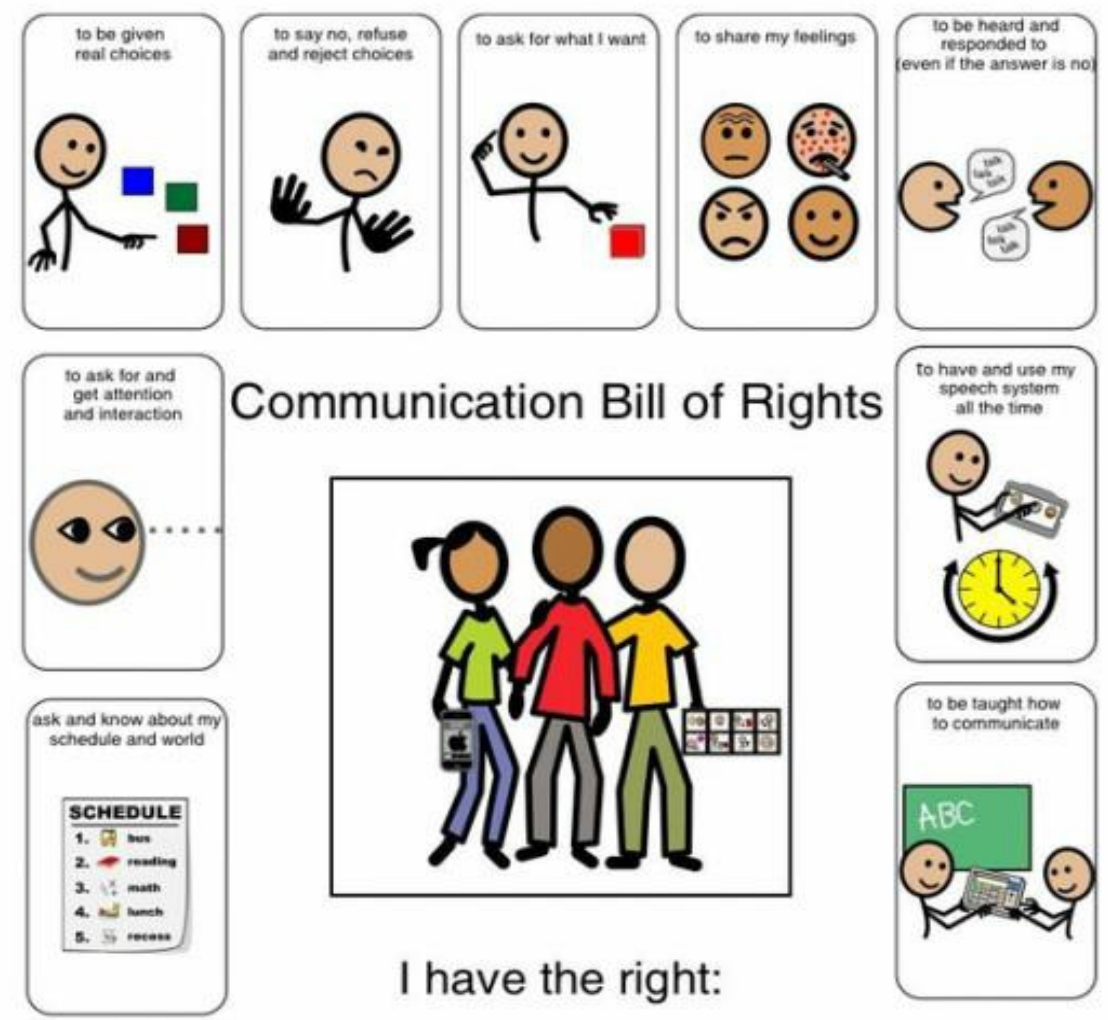

I have the right:
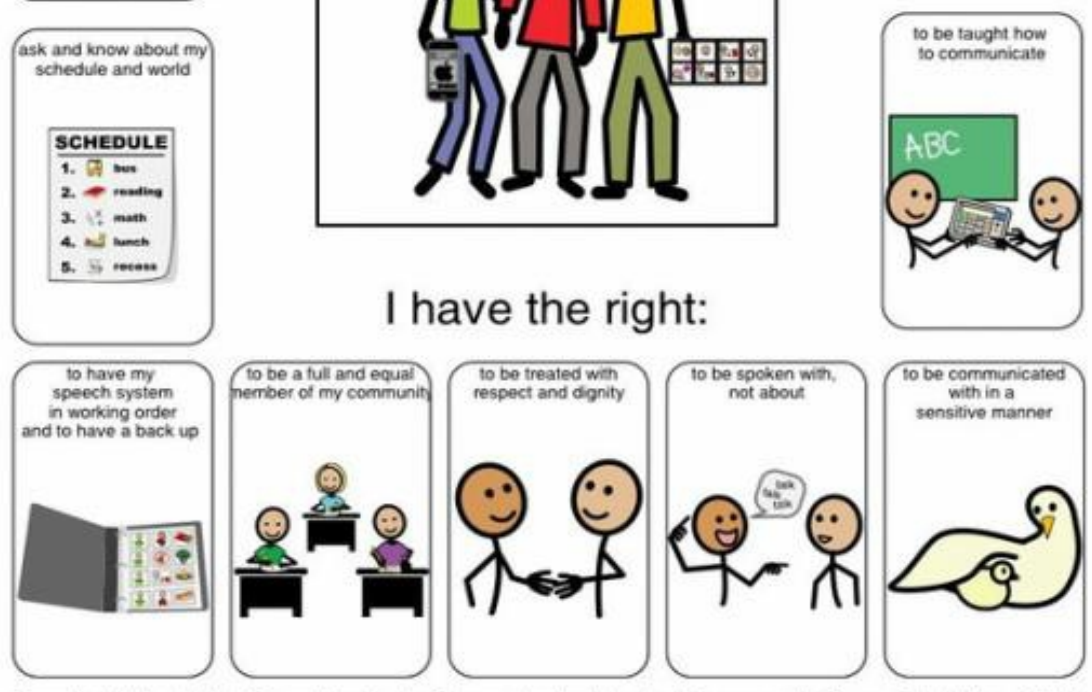

From the National Joint Committee for the Communicative Needs of Persons with Severe Disabilities. (1992). for meeting the communication needs of Dersons with severe disabilities. Asha. 34/SuDpl. 77. 2-3, adapted bv K. A

Some of these basic communication rights are as follows:

1. The right to request desired objects, actions, events, persons and express personal preferences or feelings.

2. The right to be offered choices and alternatives.

3. The right to request and be given attention and interactions with another person.

4. The right to reject or refuse undesirable objects or actions including the right to decline or reject all proffered choices. 
5. The right to have access at all times to any needed Augmented and Alternative Communication devices and to have these gadgets in good working order. (There are 12 rights in all)

Adapted from www.asha.org/policy for the National Joint Committee for the Communication Needs of Persons with Severe Disabilities. The communication rights of children with severe learning disabilities should not be ignored or violated instead, they should be observed at all costs.

\section{Developing Communication Skills in Children with Severe Learning Disabilities}

\section{Teaching Functional Communication Skills}

There is need for a baseline assessment of the individual children with severe learning disabilities to find out what they can or cannot do. The assessment enables service providers to plan programmes that meet the needs of the children and make decisions about their educational progress. Appropriate intervention should commence as soon as a communication delay or disorder is diagnosed (Kirk et al, 2006)

The communication skills taught to children with severe learning disabilities are functional in that they are relevant to the individual's survival and independent functioning in the community as appropriately as possible. The skills that are taught should also be age appropriate. Examples of such skills are brushing own teeth, bathing and feeding. Functional skills are necessary in everyday environments. These can be used immediately by the learner and they should increase the individual's independence to some extent. An ecological inventory can be conducted to identify the much needed skills for the child with SLD (Baine, 1991).

When learners acquire functional communication skills they are able to express themselves without resorting to problem behaviours or experience communication breakdown. When children and adults can functionally communicate, they are ready to learn choice making and increase their independence. The communication forms a child uses must be understood by all communication partners, particularly if the forms are not conventional or only approximate conventional words and signs (Falvey, 1995).

The content to be taught should be task analysed i.e. broken down into small -to-teach steps. After each step is mastered the child proceeds to the next. As the concept is taught in the classroom, experiences should be extended into the community so that the child is able to generalize (Mental Health Foundations, 2018). The teacher should ensure that the skills that have been learnt by the child with severe learning difficulties should be applied in other settings. This is a very difficult task for both the teacher and the student. Each small step in what might seem to be a simple task, must be repeated in a variety of settings. The teacher should develop his or her own criterion- 
referenced tests which are ecologically based to assess the child's skills (Baine, 1991).

However, children with severe learning difficulties may find themselves in situations in which competent social partners are not present (for example, a self contained special education classroom), and the behaviours they have to use for communication are not clear to others. In addition, these individuals may have severe limited life experiences, leaving little to talk about and very few reasons to communicate (www.brookespublishing.com). Children with severe learning difficulties who are in hospital schools like St Francis' Home, in Zimbabwe, tend to have extensive interactions with adult caregivers but limited interactions with peers. Not only can this lack of social opportunity make it difficult for individuals with severe learning disabilities to learn communication skills, but that it can interfere with their ability to make friends (Richardson, 2002, on line)

\section{The Intensive Interaction Approach}

The Intensive Interaction Approach is used to offer services to individuals who are difficult to reach or have not yet learned the fundamentals of early social communication. It is a means of developing interaction skills in individuals who are typically very withdrawn (Berry, Firth, Leeming and Sharma, 2014). The teaching of communication skills should relate to the natural methods as much as possible. The Intensive Interaction Approach should be employed when teaching children and adults with severe learning difficulties who are still in the early stages of communication development. It creates a communication environment that is enjoyable and non- threatening to the individual (Nind and Hewett, 2005).

The question then should not be whether learners with severe learning difficulties will benefit from communication interventions but rather how best to provide that support. It is often hard to know what support is available to assist children with SLD (Mental Health Foundations, 2018). Intensive Interaction is an approach focusing on the teaching of fundamentals of communication concepts and performance that precede speech. The fundamentals of communication are typically referred to as being attainments such as:

- Enjoying being with another person

- Developing the ability to attend to that person

- Concentration and attention span

- Taking turns in exchange of behaviours

- Using and understanding eye contacts

- Sharing personal space

- Using and understanding physical conducts (Nind and Hewett, 1998). 
This method of communication tries to create a communication environment that is enjoyable and non-threatening to the individual with severe learning difficulties. Berry, et al, (2014) observe that Intensive Interaction is a socially interactive approach to developing the pre-verbal communication and sociability of children with SLD. The teacher enjoyably works from the behaviour of the learner. The approach has a basis in the way mothers start to communicate naturally with their developing infants, where interactions are short and repetitive, involving noises, touch and eye contact. The infants generally take the lead. Activities must be highly interactive and responsive with the teacher working enjoyably from the behaviour elicited by the learner. Intensive Interaction has been found to be beneficial for building positive relationships between clients and carers (Hutchinson and Bodicoat (2015). In order to have good progress the activities should occur frequently, daily or day after day just like what the mothers do with their babies. Give the children time to take in what has been said, communicate more slowly than is normally done. The Intensive Interaction Approach is intended to address the needs of people who are non-verbal with few or limited communication behaviour (Caldwell, 2007).

\section{Augmentative and Alternative Communication (AAC)}

Augmentative and Alternative Communication devices have been developed to help students who are non-vocal to communicate. (Beukelman and Mirenda (1992). High and low technology devices can be used depending on the individual needs of the learner. Low technology devices include pictures on drawings at which the student points in order to convey meaning. The communication board is one such device that "speaks" for children with severe learning difficulties. It is one example of an AAC low technology device. The essential elements are the board itself and the symbols or pictures drawn or pasted on it. The symbols and pictures selected depend on the learners' needs and the environment in which he or she lives. Pictures should be selected according to what students need and want to communicate. High technology devices can provide voice output for example, speech synthesizers which can be programmed with many messages (www.ehow.com).

Learners with severe learning difficulties can use assistive technology to help them to communicate with others. Voice output devices, text to voice, voice to text software, touch screens that give choices for communication and translating devices can provide a lifeline for those whose speech is profoundly affected (www.ehow.com). Assistive technology (AT) assists people with severe learning difficulties to perform tasks. The assisted tasks may be anything from communication to daily living or even recreation. Children with severe learning disabilities deserve the same learning opportunities as 
other students. AT can help to ensure the enforcements of children's communication

rights.

\section{Conclusion}

It seems a logical move to borrow ideas from the natural interactive processes between mother and child in order to ignite the communicative learning of children with severe learning disabilities. These children are frequently considered communicatively difficult to reach, and are often living in some extensive social isolation. Let us respect the children's rights and enable them to develop the much needed communication skills. Remember children with severe learning difficulties are first and foremost human beings who should be supported fully to enable them to realise the benefits of effective communication resulting in more control over their lives, less frustration and stronger bonds with friends and family.

\section{References:}

1. Baine, D. (1991). Handicapped Children in Development Assessment Curriculum and Instruction. Edmonton: University of Alberta.

2. Berry, R. Firth, G. Leeming, C. and Sharma, V. (2014). Clinical Psychologists View of Intensive Interaction as an Intervention in Learning Disability Services.

3. Beukelman. D, and Mirenda, P.C. (1992). Augmentative and Alternativ Communication. Baltimore: Brookes.

4. Caldwell, P. (2007). From Isolation to Intimacy: Making Friends without words.

5. London: Kingsley Publishers.

6. Cowder, P. (2010). Communication and Conflict. Niagara: Niagara University.

7. aabri.com/manuscripts10517.pdf Accessed on 14-02 18.

8. Falvey, M. A. (Ed) (1995). Inclusive and Heterogeneous schooling. Baltimore: Brookes.

9. Hutchinson, N. and Bodicoat, A. (2015). The Effectiveness of Intensive Interaction: A Systematic Literature Review.

10. Kirk, S.A., Gallagher, J.J. and Anastasiow, N. J. (2006). Educating Exceptional Children. ( $9^{\text {th }}$ Edition) Boston: Houghton Mifflin.

11. Lowth, M. (2016). General Learning Disability. https;//patient.info/doctor/general-learning-disability. Accessed on 26-03-18.

12. Mental

Health

Foundation

(2018). https://www.mentalhealth.org.uk/learningdisability

13. Accessed on 18-04-16 
14. Nind, M. and Hewett, D. (1988). Interaction as curriculum. British Journal of Special Education. 15. (2). 55-57.

15. Nind, M. and Hewett, D. (2005). Developing Basic Communication with People Who Have Severe Learning Difficulties. New York: David Fulton Publishers.

16. Speech, Language and Communication Therapy. (2018) lcommunicatetherapy.com

17. Accessed on 13- 02- 18

18. Parenting and Child Health_(2018). Communication Difficulties in Children.

19. www.cyh.com/health topics/Health Topic Detail.

20. Teaching communication skills to students with severe Disabilities.

21. www.brookespublishing.com/store/books 20/04/12

22. www.ehow.com $16 / 04 / 16$

23. www.definitions.net $16 / 04 / 16$

24. www./lcommunicate therapy.com/program $18 / 04 / 16$

25. www.asha.org/policy

28/04/16 